\title{
General Psychiatry Factors associated with parent engagement in DIR/Floortime for treatment of children with autism spectrum disorder
}

\author{
Nattakit Praphatthanakunwong, ${ }^{1}$ Komsan Kiatrungrit, ${ }^{2}$ Sirichai Hongsanguansri, ${ }^{2}$ \\ Kaewta Nopmaneejumruslers ${ }^{3}$
}

To cite: Praphatthanakunwong N, Kiatrungrit K, Hongsanguansri S, et al. Factors associated with parent engagement in DIR/ Floortime for treatment of children with autism spectrum disorder. General Psychiatry 2018;31. doi:10.1136/ gpsych-2018-000009

- Prepublication history for this paper is available online. To view these files, please visit the journal online (http://dx.doi.org/ 10.1136/gpsych-2018-000009).

Received 23 February 2018 Revised 22 May 2018 Accepted 24 May 2018

Check for updates

(C) Author(s) (or their employer(s)) 2018 . Re-use permitted under CC BY-NC. No commercial re-use. See rights and permissions. Published by BMJ.

'Joint curriculum program by Faculty of Medicine Ramathibodi Hospital, Faculty of Medicine Siriraj Hospital and National Institute for Child and Family Development, Mahidol University, Nakhon Pathom, Thailand

${ }^{2}$ Psychiatric Department, Ramathibodi Hospital, Mahidol University, Bangkok, Thailand ${ }^{3}$ National Institute for Child and Family Development, Mahidol University, Nakhon Pathom, Thailand

Correspondence to

Komsan Kiatrungrit;

komsan.kei@gmail.com

\section{ABSTRACT}

Background The Developmental, Individual-differences, Relationship-based model (DIR/Floortime) is one of the well-known therapies for autism spectrum disorder (ASD), in which its main principle is to promote holistic development of an individual and relationships between the caregivers and children. Parental engagement is an essential element to DIR/Floortime treatment and involved with various factors. Finding those supporting factors and eliminating factors that might be an obstacle for parental engagement are essential for children with ASD to receive the full benefits of treatment.

Aim To examine the association between parents, children and provider and service factors with parental engagement in DIR/Floortime treatment.

Methods This is a cross-sectional study of parents with children aged 2-12 years who were diagnosed with ASD. Data were collected using a parent, child, provider and service factors questionnaire. Patient Health Questionaire-9, Clinical Global Impressions-Severity and Childhood Autism Rating Scale were also used to collect data. For parent engagement in DIR/Floortime, we evaluated quality of parental engagement in DIR/Floortime and parent application of DIR/Floortime techniques at home. Finally, Clinical Global Impressions-Improvement and Functional Emotional Developmental Level were used to assess child development.

Results Parents who were married, had lower income and higher knowledge of DIR/Floortime theory were more likely to have higher parent engagement $\left(\chi^{2}=4.43, p=0.035\right.$; $\chi^{2}=13.1, p<0.001$ and $\chi^{2}=4.06, p=0.044$ respectively). Furthermore, severity of the diagnosis and the continuation of the treatment significantly correlated with parent engagement $\left(\chi^{2}=5.83, p=0.016\right.$ and $\chi^{2}=4.72, p=0.030$ respectively). It was found that parents who applied the techniques for more than 1 hour/day, or had a high-quality parent engagement, significantly correlated with better improvement in child development $(t=-2.03, p=0.049$; $t=-2.00, p=0.053$, respectively).

Conclusion Factors associated with parents, children, and provider and service factors had a significant correlation with parent engagement in DIR/Floortime in which children whose parents had more engagement in DIR/Floortime techniques had better improvement in child development.

\section{INTRODUCTION}

Autism spectrum disorder (ASD) is a neurodevelopmental disorder that affects one's social interaction, communication skill, interest and behaviours. ${ }^{12}$ According to the US Centers for Disease Control and Prevention, it was found that the prevalence rate of ASD has increased from 3 to 4 in 10000 children to 9 in 10000 children in 2016 with a male-to-female ratio of $4: 1{ }^{3}$ In Thailand, it has been shown that the prevalence of ASD in children between the ages of 1 year and 5 years is 9.9 in $10000 .{ }^{4}$ Furthermore, later studies found that the prevalence increased to 1 in 250 children in Thailand, which may be due to an increase in prevalence or an increase in diagnosis now that there is more awareness surrounding ASD. ${ }^{5}$ The Ministry of Public Health stated in their most recent research that there are about 180000 Thai children who have been diagnosed with ASD. ${ }^{6}$

One of the well-known forms of therapy for ASD is Developmental, Individual-differences, Relationship-based model (DIR/ Floortime), which was created by Greenspan and colleagues. DIR's main principle is to promote holistic development of an individual and relationships between the caregivers and children through three essential methods. First, Floortime is a technique that helps child development by having children and caregivers play or do activities together. Second, home-based practice is the time when parents/caregivers help children develop certain skills that might be a challenge for them. Finally, individual therapy sessions with therapists ${ }^{17}$ that help develop relationships between caregivers and children that benefit children's communication, emotions, needs and logic. ${ }^{1}$ According to Pajareya and Nopmaneejumruslers, ${ }^{3}$ they found that after parents received DIR/Floortime training for 
3 months, they were able to better help their children's emotional and social development. Therefore, parental engagement in DIR/Floortime is an essential element for child improvement. Furthermore, there are various studies that show many parents' related factors such as lower socioeconomic status family, knowledge, motivation, stress and attitudes towards treatment and their child affect parents' involvement in the therapy ${ }^{8-10}$ There is research about parents' involvement in using applied behavioural analysis (ABA) on children with ASD aged 3-5 years. The results show various family factors (ie, the number of children, being a single parent, parents' perspective towards the diagnosis) affect parent engagement in the ABA. ${ }^{11}$ Additionally, factors within the child are important as well, for example, if a child has severe ASD, it might negatively affect the parent-child relationship and lead to poor parental involvement. ${ }^{12}$ Furthermore, factors including the therapists and techniques they use also play a big role in parent engagement. ${ }^{13} 14$ Client perceptions of their therapists' acceptance and understanding, commitment, motives to act in the clients' best interests, ${ }^{15}$ compassion, ${ }^{16}$ empathy and interpersonal skills ${ }^{15} 1718$ were all positively associated with participation, and if the techniques were too difficult, it could also affect parental engagement as well. ${ }^{19}$ As mentioned above, parent engagement is essential to various interventions for ASD children, and various factors are involved. There are many studies about parental factors related to involvement in $\mathrm{ABA}$ and pivotal response techniques. None of them study parent factors related to involvement in DIR/Floortime. Hence, it is crucial to acknowledge factors associated with parent engagement in DIR/Floortime treatment, which is our research question in this study. Our findings may be of help in supporting parental engagement in therapy and removing obstacles to their participation in the process.

\section{METHODS}

\section{Participants}

This study was a cross-sectional survey with the following inclusion and exclusion criteria for the sample: inclusion criteria: (1) parents with children aged 2-12 years who were diagnosed with ASD and received more than three sessions of DIR/Floortime at the National Institute for Child and Family Development (NICFD); (2) children who were diagnosed with ASD by psychiatrists or paediatricians according to the Diagnostic and Statistical Manual of Mental Disorders, Fourth Edition, Text Revision (DSM-IV-TR) ${ }^{20}$ and (3) parents who were included must have to lived with their children for at least 1 year. Exclusion criteria were the following: (1) children who had a disability or were diagnosed with specific syndromes such as Down's syndrome or Rett syndrome.

The required sample size calculated using Yamane's formula ${ }^{21}$ (with an error of $10 \%$ and with $95 \%$ confidence coefficient) was 37 participants. Eight participants $(20 \%$ of calculated sample size) were added to compensate for

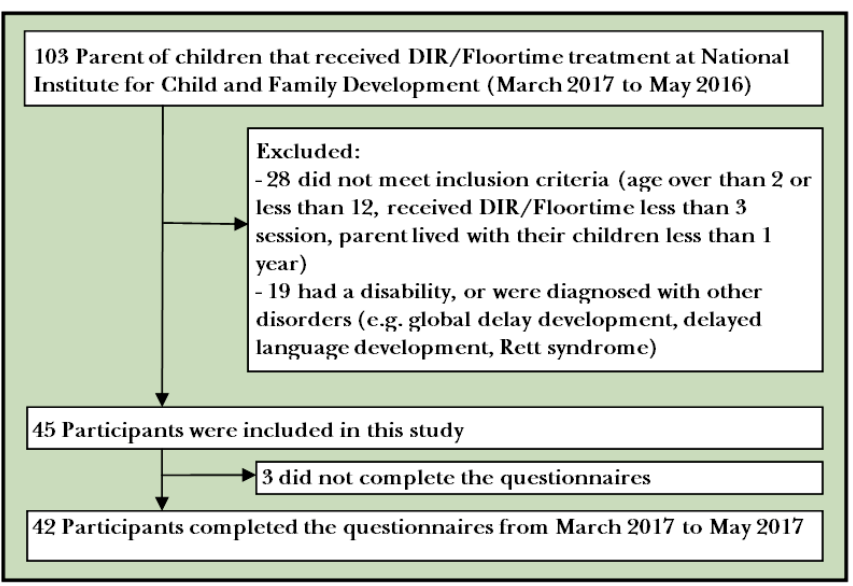

Figure 1 Flow chart of the study. NICFD, National Institute for Child and Family Development.

drop-out or missing data. The total number of participants required for this study were therefore 45 . The data were collected from 15 March 2017 to 15 May 2017, in which 103 parents of children that received DIR/Floortime treatment came to NICFD during that time. Twenty-eight of them were excluded due to not meeting inclusion criteria (eg, were not aged between 2 years and 12 years, received less than three sessions of DIR/Floortime or parent lived with their child less than 1 year), 19 of them had a disability or were diagnosed with other disorders (eg, global delayed development, delayed language development and Rett syndrome) and 11 declined to participate (figure 1). Participants were informed about the data collecting method, and informed consent was obtained. This study received ethical approval from the Mahidol University Central Institutional review board (certification number MU-CIRB 2017/002.0501).

\section{Therapists}

Therapists needed to have more than 5 years' experience with DIR/Floortime at NICFD. Moreover, they had to go through DIR/Floortime and have the required skills and knowledge about DIR/Floortime.

\section{Research instruments}

Part 1: parental factors were collected using a questionnaire that we developed. First, the general information questionnaire consisted of parental gender, age, occupation, marital status, primary caregivers (father/mother, not father/mother), family size (single/extended family), number of children in family, level of education and monthly income. Second, knowledge of DIR/Floortime techniques questionnaire that contained eight questions related to the fundamental knowledge of DIR/Floortime usage were used in order to evaluate the knowledge of DIR/Floortime principles. The questionnaire was written in multiple-choice form with 1 point for the correct answer to each question. Despite this questionnaire being developed by researchers, psychologists and paediatricians who were experts in DIR/Floortime techniques, 
the Cronbach's alpha coefficient was equal to 0.525 . Third, we administered the attitude towards ASD (four items) and DIR/Floortime techniques (five items) questionnaire, which were developed by our team. There are four options (strongly agree, agree, disagree and strongly disagree) for each item. Sum score were divided into two groups: excellent ( $>28$ points) and fair ( $\leq 28$ points) attitude towards ASD and DIR/Floortime techniques. The reliability and content validity of the questionnaire were excellent (Item-Objective Congruence by three experts was 0.96 , and Cronbach's alpha was 0.832 , respectively).

To measure the severity of depression in parents, we used the Patient Health Questionaire-9 Thai version. This questionnaire consisted of nine questions with four options (not at all, several days, more than half the days and nearly every day). Sum score was divided into five groups: minimal depression (0-4 points), mild depression (5-9 points), moderate depression (10-14 points), moderate severe depression (15-19 points) and severe depression ( $>20$ points). The Cronbach's alpha coefficient equaled 0.79 with the validity consistently with the Hamilton Rating Scale for Depression equal to 0.56 (sensitivity $=53 \%$, specificity $=98 \%) .{ }^{22}$

Part 2 included child factors such as gender, age and severity of diagnosis. Severity of the diagnosis was collected using the Clinical Global Impressions-Severity (CGI-S) (Cohen's kappa by two independent assessors $=0.69$ ). In addition, the Childhood Autism Rating Scale (CARS), which is a therapist rating questionnaire, was also used to evaluate the severity of ASD. It contains 15 questions with Cronbach's alpha coefficient equal to $0.79^{23}$ (the Cronbach's alpha was equal to 0.908 in this study).

Part 3 was provider and service factors collected by using questionnaires that we developed. First, regarding relationship with their therapists, we ask the participants, 'How is your relationship between you and the DIR/Floortime therapists?'. There are three options (excellent, fair and not good) for this question. Finally, duration of the treatment was asked using the question 'How long ago did you start using DIR/Floortime with your children?'. We left blank spaces to answer this question in years and months format.

Finally, in part 4, parent engagement was evaluated by using an evaluation form that we developed. First, the therapist evaluated the quality of parent engagement in DIR/Floortime, which included three components: (1) coaching, which is the parent's attention to advice given by therapist while they are interacting with the child. We asked them with the question, 'How much attention does your parent pay to your advice?' to evaluate this component. (2) Modelling, which is the parent's attention while observing the therapist using DIR/Floortime techniques with children. We ask them the question, ' How much attention does your parent pay to you while you are using DIR/Floortime with their children?'. There are five options for both questions (not interested $=1$, sometime $=2$, often $=3$, always $=4$, always and ask questions when they are in doubt=5). (3) Reflection, which is the parent's reflection on what they have learnt in each therapy session. We assess this component with the question, 'How much do parents reflect what they learn from the sessions?'. There are five options for this question (do not reflect $=1$, poorly reflect $=2$, fairly reflect $=3$, reflect well $=4$ and perfectly reflect $=5$ ). Sum scores were divided into two groups: high ( $>10$ points) and low $(\leq 10$ points) to measure quality of parent engagement in DIR/ Floortime. Inter-rater reliability for the whole questionnaire and reflection components was excellent (Cohen's kappa $=1.00)$ but moderate for coaching and modelling components (Cohen's kappa $=0.412,0.444$, respectively).

Second, we evaluated how much parents use the DIR/ Floortime technique at home with their child by having them fill out answers in a blank space. The questionnaire included questions about time spent on using DIR/ Floortime techniques per day (How much do you spent on using DIR/Floortime techniques with your child per day?), practising daily life skills (How much do you spend on practicing daily life skills per day?) and structured activities at home per day (How much do you spend on practicing structured activities at home per day?).

Part 5: for improvement of child's development, Functional Emotional Developmental Level (FEDL), which is clinical ratings evaluation by therapist developed by Solomon and colleagues, was used. ${ }^{24}$ The therapist assesses the child's holistic development and emotional and social development, which had six steps according to DIR/Floortime theory as the following: (1) calm regulation and attentiveness; (2) relationship with others; (3) emotional intent; (4) problem-solving communication; (5) emotional ideas; and (6) logic. Each step was divided into 0.5 point. To find the FEDL difference, we subtract the sum score of the FEDL at last session with the sum score of the FEDL when the child started the therapy (as recorded in the medical records). We also used the Clinical Global Impressions-Improvement (CGI-I) scale to assess improvement of child's development with seven options (1=very much improved, $2=$ much improved, $3=$ minimally improved, $4=$ no change, $5=$ minimally worse, $6=$ much worse and $7=$ very much worse), the inter-rater reliability of the CGI-I was almost perfect (Cohen's kappa of 1.00). We found that the FEDL difference was significantly correlated with the CGI-I score $(r=-0.494, \mathrm{p}=0.001)$.

\section{Statistical analysis}

Statistical analysis was done with SPSS V.22.0. Descriptive statistics were used to report frequency, percentage, mean and SD for demographic data, parents, child, and provider and service factors, together with parent engagement and improvement of child development. $\chi^{2}$ test was used to report association between parent, child, and provider and service factors and parent engagement (likelihood ratio was used to test association in low-frequency variants rather than Fisher's exact test, due to recent studies that found comparable statistical result. ${ }^{25}{ }^{26}$ t-Test was used for comparing the average score between parent engagement and improvement of child development. 


\section{RESULTS}

\section{Demographic data}

The group consisted of 42 participants of whom 31 were female $(73.8 \%)$. The mean(SD) age of participants was 40.93 (7.73) years old. Thirty-one of them had an occupation $(73.8 \%)$ and 38 of them were living with their spouses $(90.5 \%)$. Thirty-five of the participants were father/mother $(83.3 \%)$, and 26 of them were single family $(61.9 \%)$. As for the education level, there were 27 people who obtained a Bachelor's degree or lower $(64.3 \%)$. For monthly income, there were 22 of the participants with a monthly income more than 50001 baht $(52.4 \%)$. As for children, there were 42 participants of which 33 were boys $(78.6 \%)$ with a mean (SD) age of $6.07(0.45)$ years old and 26 of them were still in early childhood (61.9\%). Furthermore, 10 of them were using psychotropic medication $(23.8 \%)$ (table 1$)$.

\section{Parent, child, and provider and service factors}

Parents had a mean (SD) score of $6.88(0.20)$ points for the knowledge of DIR/Floortime, while 17 (40.5\%) and 18 of parents $(42.9 \%)$ had minimal and mild depression, respectively. As for the score reflecting attitude towards $\mathrm{ASD}$ and DIR/Floortime techniques, the mean (SD) total score was $31.71(0.54)$ points (14.02 (0.22) and 17.69 (0.44) points for the average of the attitude towards ASD and DIR/Floortime techniques, respectively).

As for children, the mean (SD) age that they started the treatment was $3.54(0.26)$ years old. The CGI-S scores showed that 17 of the children $(40.5 \%)$ were equally in moderately and markedly level of severity. Once the severity was assessed by CARS, it was found that there were $32(76.2 \%)$ children who were severe.

As for providers, there were $95.2 \%$ of the parents that had an excellent relationship with the therapists. The mean (SD) duration of treatment was 30.62 (4.31) months (table 2).

\section{Parent engagement in DIR/Floortime}

Seventeen parents $(40.5 \%)$ had a high-quality engagement in DIR/Floortime. The mean (SD) time parents spent on using DIR/Floortime techniques, practiing daily life skills and structured activities with their children at home were 140.95 (20.65), 104.76 (12.73) and 82.26 (11.08) minutes/day, respectively (table 3 ).

\section{Improvement in child development}

Most children had the level of child development, as assessed by FEDL, equal to 1.0 (35.7\%) on starting DIR/ Floortime techniques and equal to $3.0(21.4 \%)$ at the last visit. The mean (SD) FEDL score difference was equal to 2.25 (0.16). For the CGI-I, it was showed that 21 children were much improved $(50.0 \%)$ and 19 children were minimally improved (45.2\%).

Correlation between parents, children, and provider and service factors with parent engagement in DIR/Floortime Parents who lived with their spouses tended to help children practice daily life skills more than 1 hour/day, which was

\begin{tabular}{|c|c|c|c|c|}
\hline & $\mathbf{N}$ & $\%$ & $\begin{array}{l}\text { Mean } \\
\text { (SD) }\end{array}$ & Min-max \\
\hline \multicolumn{5}{|l|}{ Parent } \\
\hline \multicolumn{5}{|l|}{ Gender } \\
\hline Male & 11 & 26.2 & & \\
\hline Female & 31 & 73.8 & & \\
\hline \multicolumn{5}{|l|}{ Age } \\
\hline Early adult (20-40 years) & 18 & 42.9 & \multirow{2}{*}{$\begin{array}{l}40.93 \\
(1.19)\end{array}$} & \multirow[t]{2}{*}{ 25-64 } \\
\hline Middle adult (41-64 years) & 24 & 57.1 & & \\
\hline \multicolumn{5}{|l|}{ Occupation } \\
\hline Employed & 31 & 73.8 & & \\
\hline Unemployed (housewife) & 11 & 26.2 & & \\
\hline \multicolumn{5}{|l|}{ Status } \\
\hline Living with spouses & 38 & 90.5 & & \\
\hline Widow/divorce/separated & 4 & 9.5 & & \\
\hline \multicolumn{5}{|l|}{ Primary caregivers } \\
\hline Father/mother & 35 & 83.3 & & \\
\hline Not father or mother & 7 & 16.7 & & \\
\hline \multicolumn{5}{|l|}{ Family size } \\
\hline Single family & 26 & 61.9 & & \\
\hline Extended family & 16 & 38.1 & & \\
\hline \multicolumn{5}{|l|}{ Education level } \\
\hline Bachelor's degree or lower & 27 & 64.3 & & \\
\hline Higher than Bachelor's degree & 15 & 35.7 & & \\
\hline \multicolumn{5}{|l|}{ Income } \\
\hline Less than or equal to 50000 baht & 20 & 47.6 & & \\
\hline More than 50000 baht & 22 & 52.4 & & \\
\hline \multicolumn{5}{|l|}{ Child } \\
\hline \multicolumn{5}{|l|}{ Gender } \\
\hline Male & 33 & 78.6 & & \\
\hline Female & 9 & 21.4 & & \\
\hline \multicolumn{5}{|l|}{ Age } \\
\hline Early childhood (2-6 years) & 26 & 61.9 & \multirow{2}{*}{$\begin{array}{l}6.07 \\
(0.45)\end{array}$} & \multirow[t]{2}{*}{$2-12$} \\
\hline Middle childhood (7-12 years) & 16 & 38.1 & & \\
\hline \multicolumn{5}{|l|}{ Psychotropic medication use } \\
\hline Yes & 10 & 23.8 & & \\
\hline No & 32 & 76.2 & & \\
\hline
\end{tabular}

more than parents who were widows/widowers, divorced or separated $\left(\chi^{2}=4.43, p=0.035\right)$. Parents who earned less than or equal to $50000 \mathrm{baht} / \mathrm{month}$ tended to spend time on using DIR/Floortime techniques with their children more than 2 hours/day when compared with parents who earned more monthly $\left(\chi^{2}=13.1, p<0.001\right)$. In addition, parents who had higher scores of knowledge about DIR/Floortime $(>6$ points) tended to have more parent engagement quality in DIR/Floortime than those who had lower scores ( $\leq 6$ points) $\left(\chi^{2}=4.06, p=0.044\right)$. Participants with an 'excellent' attitude (as rated by the scale) towards the diagnosis and DIR/ Floortime techniques tended to practice daily life skills with 
Table 2 Parent, child, and provider and service factors

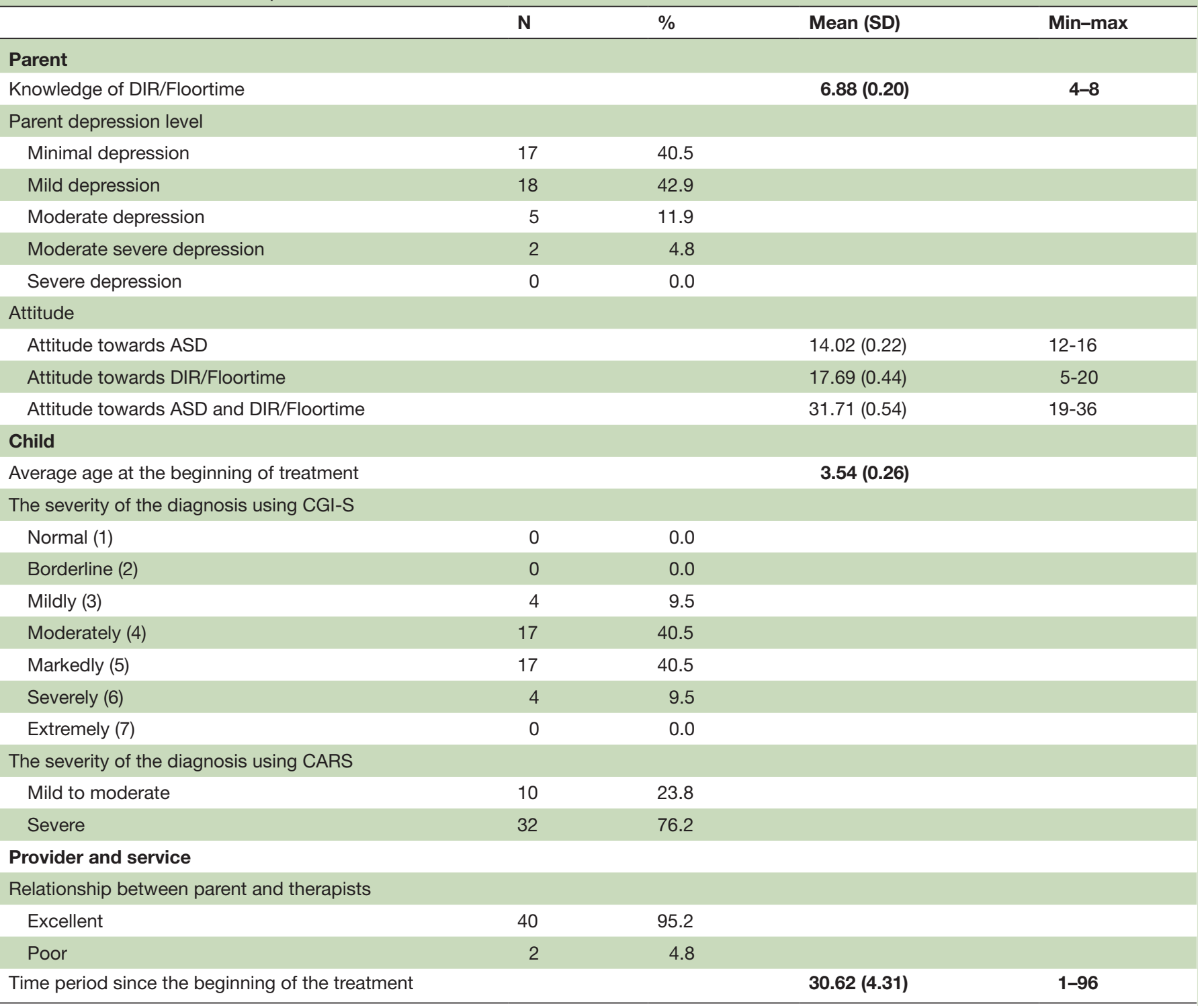

ASD, autism spectrum disorder; CARS, Childhood Autism Rating Scale; CGI-S, Clinical Global Impressions-Severity; DIR, Developmental, Individualdifferences, Relationship-based model.

their children more than 1 hour per day as compared with those whose attitude was rated as 'fair' $\left(\chi^{2}=3.65, p=0.056\right)$.

It was found that parents of children with a high severity level on the spectrum tended to spend more than 1 hour/ day practicing daily skills when compared with parents whose children were mild-to-moderate severity level $\left(\chi^{2}=5.83, p=0.016\right)$.

Additionally, in terms of factors associated with provider and service factors, it was found that parents who practised DIR/Floortime techniques for more than 48 months tended to have a higher quality of parent engagement than parents who practised less than or equal to 48 months $\left(\chi^{2}=4.72, p=0.030\right)($ table 4$)$.

Association between improvement of child developmental level and parent engagement in DIR/Floortime

Children whose parents spent more than 1 hour/day on practising daily life skills had a higher average CGI-I score than those whose parents spent less hours $(t=-2.03$, $p=0.049$ ). Additionally, children of parents with high quality of parental engagement in DIR/Floortime tended to have a higher FEDL difference score than the ones whose parents had lower quality parental engagement $(t=-2.00, p=0.053)$ (table 5).

\section{DISCUSSION \\ Main findings}

This current research found that most parents had good knowledge in DIR/Floortime techniques and a good attitude towards ASD and DIR/Floortime techniques. Most parents adequately spent their time using DIR/Floortime at home according to the principle of DIR/Floortime techniques (20-30 $\mathrm{min} /$ time and $6-10$ times/day). ${ }^{1}$ However, the sample group in this study were parents who continuously participated in DIR/Floortime techniques 
Table 3 Parent engagement in DIR/Floortime

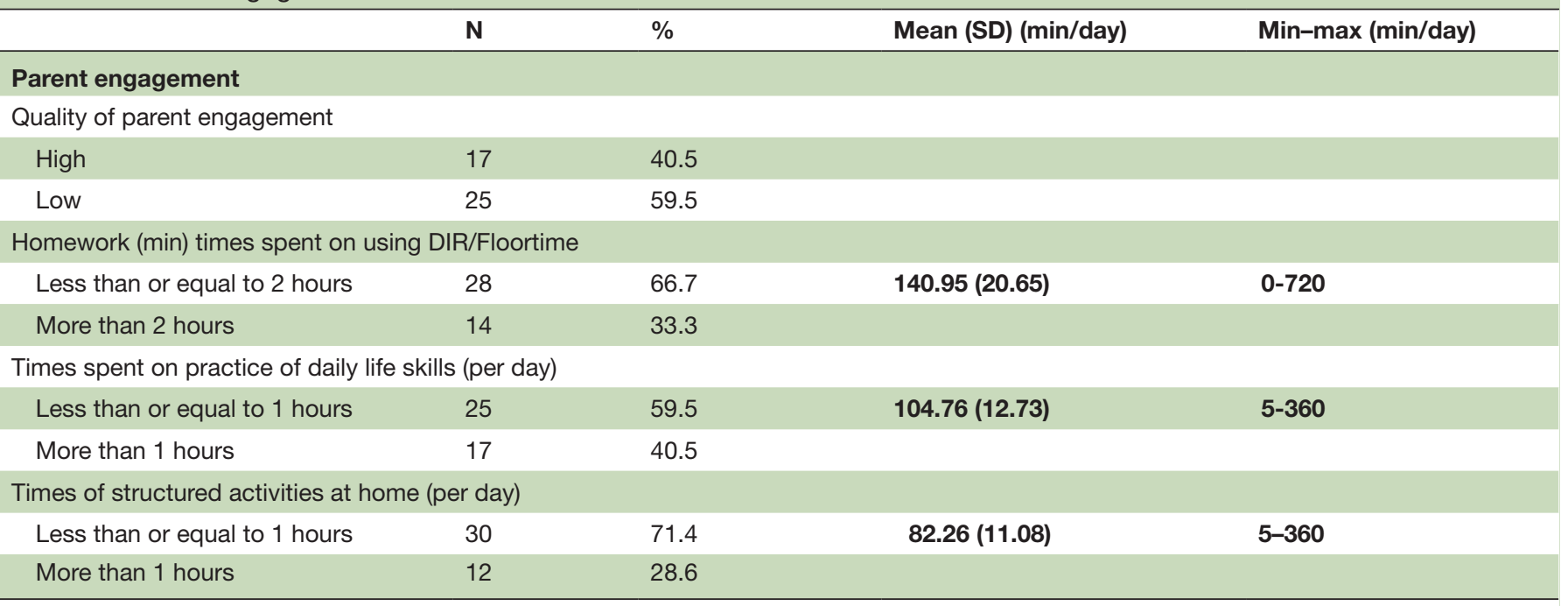

DIR, Developmental, Individual-differences, Relationship-based model.

training but did not include the samples who irregularly visited or stopped.

We found that parents who lived with spouses were more likely to be practising daily life skills with their child. This result is supported by several studies that found that parents' marital status is positively correlated with parental engagement in various interventions. ${ }^{19} 27$ Parents who were married had more skills and experiences than parents who were still single, and they already had less problems during training. ${ }^{19}$ Moreover, parents who lived with their spouses could help each other in taking care of their children. Studies also found that parents with lower income spent more time in practising DIR/Floortime techniques with their children that was opposed to the results of previous studies, which found that parents with higher income had better parental engagement. ${ }^{192829}$ Parents who earned less might not be working or have resigned from their jobs or were working at home in order to take care of and apply DIR/ Floortime techniques with their children. However, our participants were mostly employed. Furthermore, a study showed that knowledge in using DIR/Floortime techniques correlated with high-quality parental engagement. The parents who understood the techniques well felt that they were capable of using the techniques. ${ }^{30}$ We also found that parents who had a good attitude towards ASD and DIR/Floortime techniques were more likely to practice daily life skills interventions with their children. This result is supported by research that found that good attitude towards ASD and confidence in the treatment were positively correlated with good parental engagement. ${ }^{12}$ If one believed that ASD symptoms could be improved and trusted in the application of these techniques, they would be more likely to spend time using them with their children.

As for factors associated with children, we found that parents who lived with children with higher severity of ASD were more likely to practice daily skills with their children. ${ }^{14}$ There is a study showing that a factor potentially affecting parent involvement is severity, ${ }^{29}$ and parents of children who exhibit more behavioural problems (high severity) had more parent engagement. ${ }^{31}$ Parents might be worried and expect their children to have better development, so they tended to spend more time practising their children's skills.

For provider and service factors, the results showed that parents who had longer duration of treatment were more likely to have higher quality of parental engagement. Parents who had been practising the techniques for a long time would have a lot of experience and knowledge, so these would reflect in the quality of engagement in therapy.

Furthermore, this current research also found that children of parents who spent more time on practising daily life skills with them were more likely to have a higher CGI-I average score than children of parents who spent less time. Additionally, children of parents with higher quality of parent engagement were more likely to have a higher average score of FEDL difference than children whose parents had lower quality of engagement. These findings emphasise the importance of having good parental engagement, which may further improve child development. Parents with high quality of parental engagement may apply more appropriate techniques with their children both at home and during the therapy sessions that might improve their children's development. These results correlate with a study that found that parent engagement and the continuity of technique usage were major factors for increasing child developmental level. ${ }^{32}$ According to Kasari and colleagues, ${ }^{33}$ high parental engagement has a positive effect on children's joint engagement and decreases children's object-only focused engagement, which were are deficits commonly seen in patients with ASD. Similarly, in Thailand, there was research that followed children with ASD who received DIR/Floortime treatment and found that $54 \%$ 


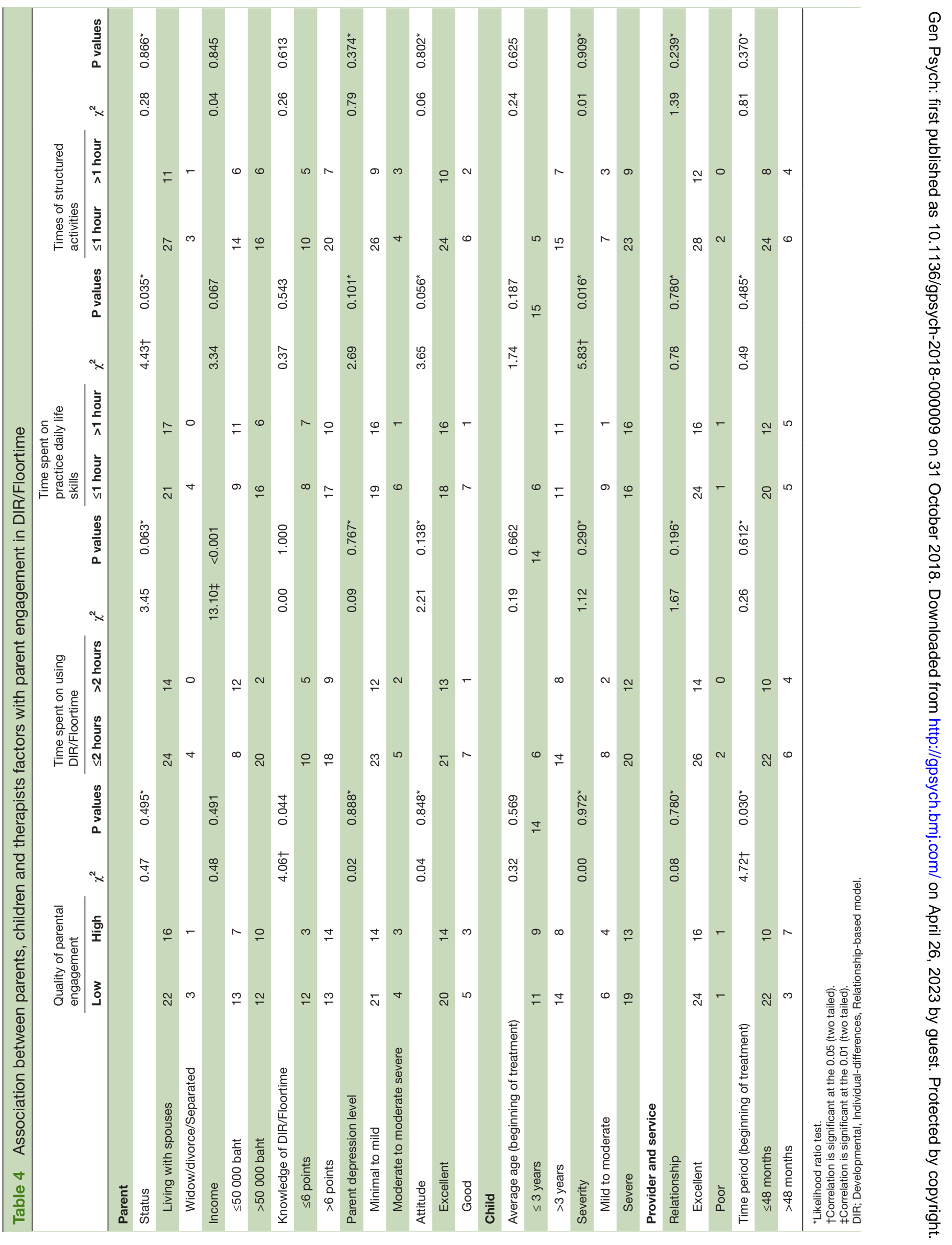


Table 5 Association between improvement of child developmental level and parent engagement in DIR/Floortime

\begin{tabular}{|c|c|c|c|c|c|c|c|c|}
\hline & \multicolumn{4}{|c|}{ Developmental improvement } & \multicolumn{4}{|c|}{ CGI-I } \\
\hline & $\mathbf{N}$ & Mean (SD) & $\mathbf{t}$ & $P$ values & $\mathbf{N}$ & Mean (SD) & $\mathbf{t}$ & $P$ values \\
\hline \multicolumn{9}{|c|}{ Quality of parent engagement } \\
\hline High & 17 & $2.62(0.23)$ & & & 17 & $2.53(0.15)$ & & \\
\hline \multicolumn{9}{|c|}{ Times spent on using DIR/Floortime (per day) } \\
\hline$>2$ hours & 14 & $2.18(0.31)$ & & & 14 & $2.5(0.17)$ & & \\
\hline \multicolumn{9}{|c|}{ Times spent on practice of daily life skills (per day) } \\
\hline$\leq 1$ hours & 25 & $2.46(0.20)$ & 1.65 & 0.106 & 25 & $2.40(0.10)$ & -2.03 & $0.049^{*}$ \\
\hline$>1$ hours & 17 & $1.94(0.25)$ & & & 17 & $2.76(0.16)$ & & \\
\hline \multicolumn{9}{|c|}{ Times of structured activities at home (per day) } \\
\hline
\end{tabular}

${ }^{*}$ Correlation is significant at the 0.05 (two tailed).

†Correlation is significant at the 0.01 (two tailed).

DIR; Developmental, Individual-differences, Relationship-based model.

of these children who regularly received the treatment had improved their emotional and social development. ${ }^{34}$ These results indicated that the main factors that help improve child development were parent engagement in using DIR/Floortime techniques, especially using such techniques in daily life and the quality of the engagement. However, our study did not find a correlation between time that parents spent using DIR/Floortime techniques with their children at home and child development. Further study should include specific skills such as communication skills, social skills, behavioural problems and joint engagement, which might also be correlated with parental engagement.

\section{Limitations}

This study has some limitations. First, even though our number of participants in this study exceed the calculated sample size, further studies should include a larger number of participants. Moreover, we did not include the samples who irregularly received or stopped the treatment. Therefore, there might be a selection bias in our participants. Second, despite our participants being diagnosed by paediatricians and child and adolescence psychiatrists according to DSM-IV-TR ASD diagnostic criteria, we did not use a gold standard instrument to diagnose, for example, the Autism Diagnostic Observation Schedule. Third, we did not use Fisher's exact test, which was usually used in other studies for analysis of small sizes. More recent studies found comparable statistical results between using likelihood ration and Fisher's exact test. ${ }^{25}{ }^{26}$ However, after using Fisher's exact test, we still found significant association between severity and time spent practising daily life skills $(p=0.031)$. Fourth, even this research examined various factors associated with parents, children and therapists, there may be some important factors that are not included in this study such as the expectations towards treatment and the motivation in receiving the treatment. ${ }^{35}$ Finally, although our study showed a correlation between parent engagement and child development, we did not include some specific skills related to ASD (eg, communication skills, social skills, behaviour problems and emotional problems) in our assessment. Therefore, these factors should be included in future studies.

\section{Implication}

Many factors such as parents marital status, income, knowledge of principles, attitude towards ASD and techniques, severity of ASD and duration of treatment had a positive correlation with parental engagement in DIR/Floortime. Therefore, an individual that uses DIR/Floortime techniques needs to consider these factors and provide appropriate assistance for each patient in order to decrease the challenges and increase supporting factors to improve parental engagement.

Acknowledgements We would like to thank the director and therapists from the National Institute for Child and Family Development for supporting and allowing us to collect data, and we would also like to thank all the participants for their cooperation in answering the questionnaire.

Contributors All authors conceived and designed the study and acquired the data. NP analysed and interpreted the data. NP and KK drafted the manuscript. The manuscript was critically revised by KK. All authors read and approved the final version of the manuscript.

Funding The authors have not declared a specific grant for this research from any funding agency in the public, commercial or not-for-profit sectors.

Competing interests None declared.

Ethics approval This study received ethical approval from the Mahidol University Central Institutional Review Board (certification number MU-CIRB 2017/002.0501) on 24 February 2017.

Provenance and peer review Not commissioned; externally peer reviewed. 
Data sharing statement No additional data are available.

Open access This is an open access article distributed in accordance with the Creative Commons Attribution Non Commercial (CC BY-NC 4.0) license, which permits others to distribute, remix, adapt, build upon this work non-commercially, and license their derivative works on different terms, provided the original work is properly cited and the use is non-commercial. See: http://creativecommons.org/ licenses/by-nc/4.0

\section{REFERENCES}

1 Pajareya K. A guide to developing autistic children (DIR/Floortime). 2553. Bangkok: Pimsri, 2018.

2 Rahman A, Divan G, Hamdani SU, et al. Effectiveness of the parentmediated intervention for children with autism spectrum disorder in south Asia in India and Pakistan (PASS): a randomised controlled trial. Lancet Psychiatry 2016;3:128-36.

3 Pajareya K, Nopmaneejumruslers K. A pilot randomized controlled trial of DIR/Floortime parent training intervention for pre-school children with autistic spectrum disorders. Autism 2011;15:563-77.

4 Khunkaew Y. Autistic: knowledge for development. Human resources development journal. 2018, 2: 144.

5 Pornnoppadol C. Autism and the pervasive developmental disorders. In: Piyasilp V, Katemarn P, eds. Textbook of child and adolescent psychiatry. Nonthaburi: beyond enterprise, 2018: 141-66.

6 Humphrey D. U.S.-Thailand prediction of regressive autism and its prevention cooperation. Journal of Applied Research in Intellectual 2008;1.

7 National Institute for Child and Family Development. Mahidol university. A guide to developing delay and special children in holistic way (DIR/Floortime) happiness version. 2558, 2018.

8 Buschbacher P, Fox L, Clarke S. Recapturing desired family routines: a parentprofessional behavioral collaboration. Research and Practice for Persons with Severe Disabilities 2004;29:25-39.

9 Burrell TL, Borrego, J. Parents' involvement in ASD treatment: what is their role? Cogn Behav Pract 2012;19:423-32.

10 Brookman-Frazee L, Koegel RL. Using parent/clinician partnerships in parent education programs for children with autism. J Posit Behav Interv 2004;6:195-213.

11 Moroz AK. Exploring the factors related to parent involvement in the interventions of their children with autism. California, 2015.

12 Hines M, Balandin S, Togher L. Buried by autism: older parents perceptions of autism. Autism 2012;16:15-26.

13 Rodger S, Keen D, Braithwaite M, et al. Mothers' Satisfaction with a Home Based Early Intervention Programme for Children with ASD. Journal of Applied Research in Intellectual Disabilities 2008;21:174-82.

14 Holdsworth E, Bowen E, Brown S, et al. Client engagement in psychotherapeutic treatment and associations with client characteristics, therapist characteristics, and treatment factors. Clin Psychol Rev 2014;34:428-50.

15 Allen JG, Newsom GE, Gabbard GO, et al. Scales to assess the therapeutic alliance from a psychoanalytic perspective. Bull Menninger Clin 1984;48:383-400.
16 VanDeMark NR, Burrell NR, Lamendola WF, et al. An exploratory study of engagement in a technology-supported substance abuse intervention. Subst Abuse Treat Prev Policy 2010;5:10-23.

17 Boardman T, Catley D, Grobe JE, et al. Using motivational interviewing with smokers: do therapist behaviors relate to engagement and therapeutic alliance? J Subst Abuse Treat 2006;31:329-39.

18 Moyers TB, Miller WR, Hendrickson SML. How does motivational interviewing work? Therapist interpersonal skill predicts client involvement within motivational interviewing sessions. J Consult Clin Psychol 2005;73:590-8

19 Clark DB, Baker BL. Predicting outcome in parent training. J Consult Clin Psychol 1983;51:309-11.

20 American Psychiatric Association. Diagnostic and statistical manual of mental disorders. 4th edn. Washington, DC: Text Revision American Psychiatric Association, 2000.

21 Yamane T. Statistics: an introductory analysis. Harper \& Row, 1967.

22 Lotrakul M, Sumrithe S, Saipanish R. Reliability and validity of the Thai version of the PHQ-9. BMC Psychiatry 2008;8:46.

23 Russell PS, Daniel A, Russell S, et al. Diagnostic accuracy, reliability and validity of Childhood Autism Rating Scale in India. World $J$ Pediatr 2010;6:141-7.

24 Solomon R, Necheles J, Ferch C, et al. Pilot study of a parent training program for young children with autism: the PLAY Project Home Consultation program. Autism 2007;11:205-24.

25 Kroonenberg PM, Verbeek A. The tale of cochran's rule: my contingency table has so many expected values smaller than 5 , what am i to do? The American Statistician 2017:1-9.

26 Choi L, Blume JD, Dupont WD. Elucidating the foundations of statistical inference with $2 \times 2$ tables. PLoS One 2015;10:e0121263.

27 Gopalan G, Goldstein L, Klingenstein K, et al. Engaging families into child mental health treatment: updates and special considerations. $J$ Can Acad Child Adolesc Psychiatry 2010;19:182-96.

28 Bennett A. Parental involvement in early intervention programs for children with autism. master of social work clinical research papers, 2012.

29 Benson P, Karlof KL, Siperstein GN. Maternal involvement in the education of young children with autism spectrum disorders. Autism 2008; 12:47-63.

30 Solomon M, Ono M, Timmer S, et al. The effectiveness of parentchild interaction therapy for families of children on the autism spectrum. J Autism Dev Disord 2008:38:1767-76.

31 Garbacz SA, Mclntyre LL, Santiago RT. Family involvement and parent-teacher relationships for students with autism spectrum disorders. Sch Psychol Q 2016;31:478-90.

32 Lovaas OI, Koegel R, Simmons JQ, et al. Some generalization and follow-up measures on autistic children in behavior therapy. $J$ App Behav Anal 1973;6:131-65.

33 Kasari C, Gulsrud AC, Wong C, et al. Randomized controlled caregiver mediated joint engagement intervention for toddlers with autism. J Autism Dev Disord 2010;40:1045-56

34 Nopmaneejumruslers K, Maisook P. Sumalrot T. A follow-up study of autistic children that using DIR/Floortime in treatment. Thai journal of pediatrics;55:284-92.

35 Hastings RP, Johnson E. Stress in UK families conducting intensive home-based behavioral intervention for their young child with autism. J Autism Dev Disord 2001;31:327-36.

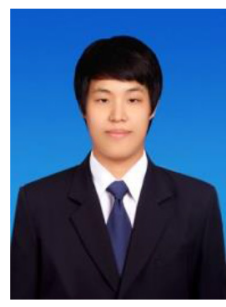

Nattakit Praphatthanakunwong obtained a bachelor's degree from Srinakharinwirot University in 2015, and currently is a graduate student in the Master of Science Program in Child, Adolescent, and Family Psychology (Joint curriculum program by Faculty of Medicine Ramathibodi Hospital, Faculty of Medicine Siriraj Hospital and National Institute for Child and Family Development, Mahidol University). His research interests include $A S D$ and children with special needs. 